\title{
Introducing evidence based public health practice through a journal club for public health officers in Somaliland
}

\author{
Jibril I M Handuleh ${ }^{a}$, Abdirahman A Sulleiman ${ }^{b}$, Yusuf S Yusuf ${ }^{c}$, Hayat Mohamed ${ }^{d}$, Daniel Fekadu Wolde- \\ Giorgis $^{\mathrm{e}}$ \\ ${ }^{\mathrm{a} S c h o o l}$ of Public Health, Amoud University, Borama, Somaliland; ${ }^{\mathrm{b}}$ The Ministry of Health, Hargeisa, Somaliland; ${ }^{\mathrm{c}}$ Monitoring

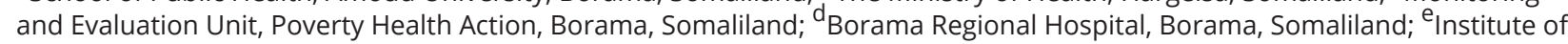 \\ Psychiatry, Psychology and Neurology, King's College London, London, United Kingdom
}

\begin{abstract}
Evidence based public health is one of the basic training tools of public health students and young officers in decision making. The training tools for early career specialists and trainees in public health is journal clubs $(\mathrm{JC})$. It keeps the knowledge of professionals up to date and assist them in receiving information to design, plan, implement health care services, policies and strategies.

The intention of the JC team was to raise awareness of methods for public health literature search, appraising it and applying this knowledge in their daily practices. A senior public health practitioner in Somaliland (the corresponding author) invited medical students and residents to have JCs as a part of their training. They did not accept the offer so the organizer invited practicing junior public health professionals instead. The JC team members were a general practitioner and 3 public health workers from Ministry of Health, public hospital physician, public health school and field public health officer. A weekly or twice weekly journal club took place to train them in critical appraisal. This continued for 15 months in a hybrid mentorship for the health care professionals.
\end{abstract}

The team mentor selected a paper for discussion. Mentees choose a study design appraisal tool from the Critical Appraisal Skills Program (CASP) that matched the study to present. In the process of appraisal, a team member led the discussion using the checklist.

The mentees presented their critical appraisal either orally or via a presentation. The checklist and paper were compared for assessing the study design and structure of the paper of the week.

This approach of empowering junior public health officers in Somalia is a way forward for encouraging the professionals to use evidence based practice in their daily practices. This will improve their selection of research tools and translating the scientific work into their practice and services.

\section{ARTICLE HISTORY}

Received 17 December 2020

Accepted 7 June, 2021

\section{RESPONSIBLE EDITOR}

Lars L Gustafsson

\section{KEYWORDS}

Evidence-based practice, journal club, literature search, public health education, public health practice, Somaliland.

\section{Background}

Journal clubs are tools for training residents in clinical specialties on critical appraisal of the literature ${ }^{1}$. The first group of people to use journal club as an educational purpose were physicians in the late nineteenth century. William Osler established a journal club at McGill University ${ }^{1}$ in Canada, he is one of the modern fathers of clinical medicine that became part of training of his medical students at the time ${ }^{2}$. A core area of a journal club is to link research with the clinical decision making process to improve the care of the patients ${ }^{3}$.

Journal clubs can be offered both in class and increasingly in digital platforms. Examples include twitter groups and sharing on LinkedIn ${ }^{4}$.

Public health considers evidence based practice (EBP) as a core competence of public health professionals ${ }^{5}$. This includes adding it as part of public health curriculum and also encouraging the EBP in the daily practice of the 
public health experts. Journal club is one of the tools of the professionals to learn different research methodologies ${ }^{6}$.

In low and middle countries public health professionals have poor access to continuous professional development. This includes attending conferences, educational opportunities while working and mentorship. This is the case even in our setting in Somaliland. Our undergraduate public health students in our setting study research methodologies, write theses but they don't regularly read journals as faculty teach based on slides with little literature appraisals.

Therefore, we started a journal club aimed to fill this gap for the Somaliland public health scientists ${ }^{7}$. Some of them will be working in areas of public health that requires using scientific tools in their practical work and a clinician for her clinical practice. The journal club comes into this post public health school education need for the Somaliland public health workers.

The objective of the paper is to report the introduction of journal clubs to Somaliland public health trainees and share how it was set up and the ways it was done.

\section{Methods}

The paper is a descriptive case study of the introduction of journal clubs. The attendees of the journal club voluntarily joined the sessions. They were junior public health professionals working in different areas of public health including Ministry of Health in Somaliland, public health faculties and international development agencies. The team leader organized a seminar on journal club principles and the execution of this academic exercise. The mentees learned appraisal techniques and how a journal club works.

The team of the JC were one general physician and three public health professionals with moderation from the lead author of the paper. This is the first journal club in Somaliland to our knowledge. We started in March 2019 continued to June 2020. The club continued for 15 months. Meetings were hybrid face to face and online via Google Meet platform. When the corresponding author was in field in Somaliland, meetings happened with a round table meeting while not available it was switched online. The paper is a report on the establishment and the practical implementation of this teaching method as a continuous professional development initiative. The moderator of the club was a senior public health professional. The team decided weekly or twice monthly to work regularly over selected papers to appraise literature. The moderator also invited medical residents in Borama and the supervisors of medical students to set up a medical journal club but this was not possible to do at that time.

The team chose areas of public health that were relevant to the public health professionals. The areas that the team regarded as important areas were infectious diseases, epidemiology, health services, health education and behavior, health policy, mental health and reproductive health services. The team also agreed to mix the research methodologies. Examples are cross sectional studies, cohort and case-control studies, randomized trails, systematic review and met analysis. Qualitative methodologies were also part of the papers selected for appraisal.

One of the junior students presented a topic per session. A critical Appraisal tool was used to critique the paper against criteria. The tool was selected at CASP (see below). Areas assessed include the following: the methodology, selection of participants, analysis and results.

The Shaah and Sheeko club (Tea and storytelling in Somali) was the way to meet for the JC presentation with serving of cookies and coffee in a hotel corner. The team used to come with their laptops. The discussions followed the sessions. The JC was also a socializing event and coaching session for junior public health professionals. A public health officer would be invited and present a paper that the moderator chose for the journal club. Sometimes, if the paper had a statistical or epidemiological area that they did not know, the moderator organized a teaching session along with the presentation.

The officers also had critical appraisal toolkit to understand the process of appraising a paper. Example of such appraisal tool is developed by the critical appraisal skills protocols organization and is available online at https://casp-uk.net/casp-tools-checklists/ ${ }^{8}$. The evaluation was based on the toolkit to assess a paper for the journal club. A PowerPoint or an oral presentation was used at the club meetings. In the oral sessions the presenter would distribute the paper and the toolkit to appraise the paper and would ask everybody to critic the paper. After filling it in, the whole team discussed the paper critically.

The number of studies discussed included areas of public health that were relevant to Somaliland public health practice, mainly addressing infectious and noncommunicable diseases including reproductive health, mental health and vaccination programs. This was for public health professionals to broaden their scope of understanding the contemporary public health practice. The journals were chosen among different reputable journals. Table 1 shows the different study design methods that had been discussed in the mentorship. The team also selected studies from different geographical areas. They acknowledged that the journal club improved their critical appraisal skills and their ability to read the literature. They pointed out the journal club was also a valuable source of improving their epidemiological skills.

The presenter and the moderator also developed a short course in writing skills for the team. The presenters gave a lecture on the research methodology after the presentation. The team found some technical errors with the papers published and for one of them the moderator wrote to the editor for a review of the paper which led to a correction of the statistical methods. 
Table 1. Journal club articles presented and discussed March 2019 to June 2020. Global studies are those conducted in more than one continent.

\begin{tabular}{|c|c|c|c|}
\hline Study design & $\begin{array}{l}\text { Area of public } \\
\text { health }\end{array}$ & $\begin{array}{l}\text { Number } \\
\text { of papers }\end{array}$ & Regions \\
\hline $\begin{array}{l}\text { Cross sectional } \\
\text { study }\end{array}$ & $\begin{array}{l}\text { Epidemiology, } \\
\text { Mental Health, } \\
\text { Maternal Health, } \\
\text { Infectious } \\
\text { diseases, } \\
\text { Occupational } \\
\text { Medicine }\end{array}$ & 6 & $\begin{array}{l}\text { Global [3], } \\
\text { Asia [2], } \\
\text { Australia [1] }\end{array}$ \\
\hline Cohort study & $\begin{array}{l}\text { Infectious } \\
\text { diseases, } \\
\text { Mental } \\
\text { Health, cancer } \\
\text { epidemiology, } \\
\text { Health financing }\end{array}$ & 8 & $\begin{array}{l}\text { Global [2], } \\
\text { Africa [3], } \\
\text { Asia [1], } \\
\text { Europe [1], } \\
\text { North America [1] }\end{array}$ \\
\hline $\begin{array}{l}\text { Case control } \\
\text { study }\end{array}$ & $\begin{array}{l}\text { Infectious } \\
\text { disease } \\
\text { and cancer } \\
\text { epidemiology }\end{array}$ & 2 & $\begin{array}{l}\text { Africa and North } \\
\text { America }\end{array}$ \\
\hline $\begin{array}{l}\text { Randomized } \\
\text { trial }\end{array}$ & $\begin{array}{l}\text { Infectious } \\
\text { disease } \\
\text { and cancer } \\
\text { epidemiology }\end{array}$ & 1 & Global \\
\hline $\begin{array}{l}\text { Systematic } \\
\text { review and } \\
\text { meta analysis }\end{array}$ & $\begin{array}{l}\text { Mental health, } \\
\text { chronic } \\
\text { diseases, Health } \\
\text { Economics, } \\
\text { infectious } \\
\text { diseases }\end{array}$ & 4 & $\begin{array}{l}\text { Global [3], } \\
\text { Europe [1] }\end{array}$ \\
\hline $\begin{array}{l}\text { Qualitative } \\
\text { study }\end{array}$ & Health services & 1 & Asia \\
\hline Total & & 23 & \\
\hline
\end{tabular}

\section{Results}

Over the course of one year the participants discussed twenty-three papers with various designs. Cohort studies eight or $35 \%$ of the papers were the top study designs the participants discussed using the critical appraisal checklist. This is followed by Cross sectional studies six papers and thereafter case control studies with two articles. Qualitative studies and systematic literature review were also selected for appraisal. Participants led one study appraisal each and it had to rotate among them. In the last sessions they added lecture on statistical analysis or epidemiological aspects. The participants showed confidence in making sense of papers they were reading. They also connected evidence with findings. For example, one of them is a field worker on primary care and tried to understand the relationship between vaccination coverage and its effective outcome. He is designing a study on perceptions of community members on extended package of health care services in Somaliland.

\section{Discussion}

This paper reports a successful implementation of Journal Clubs as a tool for training public health professionals in critical appraisal of scientific literature. We expect that this type of continuous professional development for Somali colleagues will help them understand the benefits of using evidence in their work areas. They are designing two studies as part of their annual output. They would like to study on areas like health services and infectious diseases.

A systematic literature review on managing effective journal club meetings showed that participation in journal clubs improved knowledge and critical appraisal skills 9 Nursing training also involve journal clubbing in bridging knowledge and research ${ }^{10}$. JC can also be organized via online platforms which was practical even before the Covid19 pandemic. This was practical in training professional ${ }^{11}$.

Burstein and his colleagues used structured review instrument to study if using measuring students increased the knowledge of residents using JC. It showed it was effective $^{12}$.

Trainees and junior public health professionals can run JC themselves as illustrated in clubs that residents' physicians lead and its practical ${ }^{13}$.

The culture of literature appraisal is becoming part of their routines. The participants lead the sessions, set the timetable and are seeking to identify their areas of weakness. Every one of them will set up his own club to mentor others and we intend to introduce this practice to medical schools in Somaliland and other Somali regions.

Journal clubs have health policy implications. For instances, when critically reviewing research and the evidence gaps in health policy and planning can be found and tried to be implemented using recommended gaps from scientific knowledge. This can have socio-economic and cultural benefits as it can prevent disease like vaccinations or promote wellbeing like screening programs. This can also have impact on the critical thinking of public health professionals in Somaliland. Journal clubs can easily be part of the education both at public health training and in continuous professional development.

\section{Conclusions}

A journal club is one of the tools that can help the junior public health professionals to critically appraise and implement evidence-based research in practice. Public health education can benefit from this, particularly the postgraduate programs of public health as part of the training of the students.

Open access to journals is possible in many medical schools through the World Health Organization's Hinari website where good articles can be downloaded for free ${ }^{14}$.

The authors recommend to academics and students of public health in Somali medical and public health schools to set up journal clubs in their respective universities, working areas like ministries of health and among students to appraise the literature and improve their critical and analytical skills. A small group of 5-7 members of equal and mixed gender would be a good team structure to encourage discussion and collaboration. A moderator is useful usually a peer who may have academic or experience public health scientist will help run and 
motivate journal club members.

Journal clubs are also recommended for medical schools and public health graduate schools for their students to promote a public health research mindset.

Private practitioners can also implement their journal club cafes like the one reported in this paper. This will need a teamwork and coordination among the teams that will set up such initiatives. A pre training and post training survey will be important to measure outcome of the journal clubs to improve them or study its effectiveness. In this group, this was not done. An example is selfevaluation protocol for assessing team members.

\section{Summary in Somali}

\section{CINWAAN}

Hirgelinta Farsamada Caafimaadka Guud ee ku Saleysan Aqoon Daliil Cad leh, ee Lagu soo bandhigay kulamada Joornaal Akhriska ee Naadiga Jornaalka oy ka soo qaybgaleen Masuuliin ka Hawlgala Caafimadka Guud ee Soomaliland

\section{SOOKOOBID}

Caafimaadka guud ee ku saleysan daliil cilmi ah, wuxuu ka midyahay qalabka asaasiga u ah tababaridda ardayda, waana marinka lagu gaaro go'aammada hawlaha caafimaadka guud. Aaladaha tababarka dhalinyarada bilaabaysa barashada takhasuska iyo kuwa baranaya caafimaadka guud waxaa ka mid ah kulamada joornaal akhriska ee Naadiga Jornaalka (NJ). NJ wuxu ka midyahay hababka ay ku ilaaliyaan mihnadlayaasha caafimaadka guud, xirfaddooda si ay markasta u noqoto mid la socota waqiciga iyo iney ka caawiso helidda macluumadka la xiriira naqshadeynta, qorshaynta iyo fulinta shaqada cafimadka, siyaasadda iyo istrategiyaadka cafimaadka.

Ujeedada NJ waa sare-u-qaadidda wacyiga xirfadlayaasha xagga raadinta qoraalada caafimaadka guud, qiimeyntooda iyo $u$ adeegsiga shaqo maalmeedkooda. Hawlwadeen caafimaad oo Khibrad leh oo joga Somaliland (Qoraaga maqaalka) ayaa ku casumay ardayda kuliyadda cafimaadka iyo takhaatiir takhasus ku jirta inay tababarkan NJ ka soo qayb-galaan, barnaamijkaas oo qayb ka ah tababarkooda. Kooxdani ma ay aqbalin dalabkaas, markaas ayuu isu-duwuhu ku casumay barnaamijka xirfadlayaal caafimaad oo dhallinyaro ah. Kooxda NJ wuxay ka koobnayd takhaatiir daryeelka bulshada ku hawllan iyo saddex xirfadlayaal caafimaad oo ka socda wasaaradda caafimaadka, takhaatiir ka shaqeysa isbitaalada guud, dugsiyada tababarada caafimaadka, iyo masuuliin caafimaad ee ka shaqeeya meelaha ka baxsan magalooyinka.

Waxa uu tababarkani qabsoomayey todobaadkii mar ama laba goor, waxana lagu tababarayey habka qotadadheer ee qiimeynta iyadoo la wada joogo iyo qaabka adegsiga aragga-fog, labadaba.

Hogaamiyaha tababarka ayaa soo xuli jiray maqaalada laga doodayo. Ka qaybgalayaasha tababarku waxay dooranayeen habka qiimeynta maqaalka iyaga oo raacaya barnaamijka farsamada qiimeynta naqdiga leh (Critical Appraisal Skills Program-CASP) oo u dhigma daraasada la soo bandhigayo. Marka loo hawlgelayo qiimeynta darasada xubin ka tirsan kasoo-qaybgalayaasha ayaa hoggaminayay doodisweydaarsiga isagoo adeegsanaya liska-hubinta

\section{(checklist) ee kor ku xusan.}

Dadka la tababaray waxay ku soo bandhigayeen qiimeyntooda, soo jeedin odhaah ah ama iyaga oo adeegsanaya qalab. Liiska-hubinta iyo warqadda loo istacmaalay tababarka ayaa la is-barbardhigayey si loo baaro habka loo qorsheeyey daraasada iyo qaabdhismeedka maqaalka todobaadkaas.

Habkan oo lagu xoojinayo dhalinta masuulka ka ah cilmiga caafimaadka guud ee ku dhaqan Soomaliya waa waddo loo maro si loogu dhiirri-geliyo xirfadleyda inay isticmaalaan aqoonta caddeynta ku dhisan, si ay ugu adegsadaan hawl-maalmeedkooda shaqo. Tani waxay wanaajindoontaa xulashadooda aladaha cilmi baadhista iyo iney ku gudbiyaan hawlahaas cilmiga ah adeegyadooda.

\section{Acknowledgments}

The team acknowledges the technical support of Borama Teaching Hospital and the Somaliland Ministry of Health in endorsing and supporting the supervision of their employees.

\section{Author contributions}

The authors equally contributed to the program and to the completion of the manuscript.

\section{Disclosure statement}

None to declare.

\section{Ethics and consent}

None issue of relevance.

\section{Funding}

None.

\section{Paper context}

A journal club is a teaching tool that can be used for improve critical appraisal skills of the public health professionals. In Somaliland, this is nonexistent in the public health education curriculum. This mentorship aimed to close this gap and improve the research skills of the trainees and to inspire other public health officers in the continuous development in Somaliland. The moderator and the mentees sustained the academic coaching after the club activities.

\section{ORCID}

Jibril I M Handuleh iD https://orcid.org/0000-00032662-107

\section{References}

[1] Linzer M. The journal club and medical education: over one hundred years of unrecorded history. Postgraduate Medical Journal 1987; 63:475-478.

[2] Valentini RP, Daniels SR. The journal club. Postgraduate Medical Journal 1997;73:81-85.

[3] Deenadayalan Y, Grimmer-Somers K, Prior M, Kumar S. How to run an effective journal club: a systematic review. Journal of Evaluation in Clinical Practice 2008;14:898-911.

[4] Topf JM, Sparks MA, Phelan PJ, Shah N, Lerma EV, 
Graham-Brown MP et al. The evolution of the journal club: from Osler to Twitter. American Journal of Kidney Diseases 2017;69:827-836.

[5] Milbrandt EB, Vincent JL. Evidence-based medicine journal club. Crit Care 2004;8:401-402.

[6] Crank-Patton A, Fisher JB, Toedter LJ. The role of the journal club in surgical residency programs: a survey of APDS program directors. Current Surgery 2001;58:101-104.

[7] Cramer JS, Mahoney MC. Introducing evidence based medicine to the journal club, using a structured pre and posttest: a cohort study. BMC Medical Education 2001;1:6.

[8] CASP checklist, Critical Assessment Skills Programme, 2020 [cited 2020 Nov 9]. Available from: https://casp-uk. net/casp-tools-checklists/

[9] Deenadayalan Y, Grimmer-Somers K., Prior M, Kumar $\mathrm{S}$. How to run an effective journal club: a systematic review? Journal of Evaluation in Clinical Practice 2008; 14:898-911.

[10] Goodfellow LM. Can a journal club bridge the gap between research and practice? Nurse Educator 2004;29:107-110.

[11] Chan TM, Thoma B, Radecki R, Topf J, Woo HH, Kao LS et al. Ten steps for setting up an online journal club. Journal of Continuing Education in the Health Professions 2015;35:148-154.

[12] Burstein JL, Hollander JE, Barlas D. Enhancing the value of journal club: use of a structured review instrument. The American Journal of Emergency Medicine 1996;14: 561-563.

[13] Hartzell JD, Veerappan GR, Posley K, Shumway NM, Durning SJ. Resident run journal club: a model based on the adult learning theory. Medical Teacher 2009;31:e156-e161.

[14] World Health Organization, Hinari program 2021. [cited 2020 July 17]. Available from: https://www.who.int/ hinari/en/ 